\title{
(6) OPEN ACCESS \\ Novel myokine: irisin may be an independent predictor for subclinic atherosclerosis in Behçet's disease
}

\author{
Abdullah Icli, ${ }^{1}$ Erkan Cure, ${ }^{2}$ Medine Cumhur Cure, ${ }^{3}$ Ali Ugur Uslu, ${ }^{4}$ \\ Sevket Balta, ${ }^{5}$ Sevket Arslan, ${ }^{6}$ Davut Sakiz, ${ }^{7}$ Adem Kucuk ${ }^{8}$
}

Department of Cardiology, Meram, Turkey

${ }^{2}$ Department of Internal Medicine, Recep Tayyip Erdogan Universitesi, Rize, Turkey

${ }^{3}$ Department of

Biochemistry, Recep Tayyip Erdogan Universitesi, Rize,

Turkey

${ }^{4}$ Eskisehir Military Hospital,

Eskisehir, Turkey

${ }^{5}$ Department of Cardiology,

Gulhane Askeri Tip

Akademisi, Ankara, Turkey

${ }^{6}$ Division of Allergy and

Clinical Immunology,

Department of Internal

Medicine, Necmettin

Erbakan Universitesi Meram

Tip Fakultesi, Konya, Turkey

Department of Internal

Medicine, Necmettin

Erbakan Universitesi Meram

Tip Fakultesi, Konya, Turkey

${ }^{8}$ Department of

Rheumatology, Necmettin

Erbakan Universitesi Meram

Tip Fakultesi, Konya, Turkey

\section{Correspondence to}

Dr Abdullah Icli, Department of Cardiology, Meram 42080, Turkey;

abdullahicli@yahoo.com

Accepted 13 February 2016 Published Online First

3 March 2016

Copyright () 2016 American Federation for Medical Research

\section{ABSTRACT}

Behçet's disease (BD) is a vasculitic and inflammatory disease causing endothelial dysfunction. Irisin is a metabolic hormone related to insulin resistance and endothelial functions. In this study, we investigated the relationship between irisin and carotid intima-media thickness (cIMT), which is a marker of atherosclerosis in patients with BD. 48 patients with $B D$ and 50 healthy individuals were enrolled in the study. Disease severity was evaluated by BD current activity form. Irisin, glucose, insulin, C reactive protein, erythrocyte sedimentation rate and lipid panel were examined in all patients. Homeostasis Model Assessment of Insulin Resistance (HOMA-IR) was used to calculate insulin resistance. A simple and inexpensive cIMT test was used as indicator of atherosclerosis. cIMT was $0.62(0.45-1.05) \mathrm{mm}$ in the patients, while it was $0.38(0.25-0.65) \mathrm{mm}$ in the control group $(p<0.001)$. Irisin value was found to be 197.3 $(24.8-834.2) \mathrm{ng} / \mathrm{mL}$ in the control group, while it was $85.4(4.7-471.1) \mathrm{ng} / \mathrm{mL}$ in the patient group $(p=0.007)$. There was a negative correlation between irisin level and cIMT $(r=-0.511, p<0.001)$ and HOMA-IR $(r=-0.371, p=0.009)$. Decreased irisin levels (OR $0.996,95 \% \mathrm{Cl} 0.992$ to 1.000 , $\mathrm{p}=0.041)$, male gender (OR 7.634, 95\% Cl 1.415 to 41.191, $p=0.018$ ), and HOMA-IR (OR 2.596, $95 \% \mathrm{Cl} 1.451$ to $4.643, p=0.001$ ) are independent risk factors for CIMT in patients with BD. We detected a very strong relationship between CIMT, which is an indicator of subclinical atherosclerosis, and decreased irisin levels in patients with $B D$. BD is characterized by chronic inflammation, and low serum irisin levels in BD may be related to atherosclerosis.

\section{INTRODUCTION}

Behçet's disease (BD) is a chronic, relapsing and inflammatory disease in which cardiovascular involvement has been estimated to range between $7 \%$ and $46 \% .{ }^{1}$ Main histopathological features of $\mathrm{BD}$ are characterized by acute systemic inflammation and chronic systemic vasculitis associated with endothelial cell dysfunction. ${ }^{2}$ Systemic inflammation seen in chronic inflammatory disorders contributes to cardiovascular disease (CVD) via proven mechanisms: accelerated atherosclerosis, insulin

\section{Significance of this study}

What is already known about this subject?

- Behçet's disease is a vasculitic disease characterized by inflammation.

- Patients with Behçet's disease frequently experience cardiovascular ailments.

- In various studies, it has been stated that carotid intima-media thickness is a predictive marker for cardiovascular disease development.

- Irisin is a popular myokine that is associated with increased insulin resistance and endothelial dysfunction.

What are the new findings?

- The serum irisin level of the patients with Behçet's disease was significantly lower when compared to the irisin level of the control group.

- Serum irisin levels were related to insulin resistance in patients with Behçet's disease.

- Serum irisin levels have strong negative association with carotid intima-media thickness in patients with Behçet's disease.

- Low serum irisin levels may be independent risk factor for carotid intima-media thickness.

How might these results change the focus of research or clinical practice?

- Whether or not patients will acquire atherosclerotic heart disease or be insulin resistance can be estimated by following serum irisin levels in those with Behçet's disease. Additionally, in patients with rheumatological diseases, irisin levels can be a predictive marker for atherosclerotic heart disease, and our study can guide further studies performed on these diseases.

resistance (IR), hyperglycemia, hypercoagulability, hypercholesterolemia and platelet dysfunction. ${ }^{3}$ Observational studies have supported the information that patients with pre-existing 
chronic inflammatory diseases have a dramatically increased risk for CVD at younger ages, which is related to the fact that endothelial dysfunction is considered a common initial lesion in the development of atherosclerosis. ${ }^{3}$

Endothelial dysfunction, a well-recognized index of subclinical vascular atherosclerosis that is measured by carotid intima-media thickness (cIMT) of the common carotid artery on ultrasonography, is the earliest event in vascular complications of $\mathrm{BD}$, and contributes significantly to the initiation and progression of vascular injuries in different regions of the body, causing metabolic disease complications. ${ }^{4}$ Recent studies have shown that an increased susceptibility to IR was related to chronic inflammation, endothelial dysfunction and metabolic abnormalities in patients with BD. ${ }^{5} 6$

IR is a pathological condition characterized by a decrease in insulin activity regulating blood glucose levels, and it occurs as a response to a complex interaction between metabolic and inflammatory mediators ensuring body energy balance. ${ }^{7}$ It has been reported in recent studies that irisin had the potential to become a therapeutic target for endothelial dysfunction and metabolic disorders. ${ }^{8}$ Irisin, as a novel hormone-like myokine that plays a pivotal role in energy expenditure and metabolic regulation, is mainly secreted by the heart, skeletal muscle, liver, kidneys, nerves and skin. ${ }^{9}$ Previous studies revealed the relationship between circulating irisin levels, endothelial dysfunctions and subclinical atherosclerosis in non-diabetic adult patients. ${ }^{10}$ In another recent study, it was demonstrated that serum irisin level was significantly correlated with carotid atherosclerosis in patients receiving dialysis. ${ }^{11}$ Interestingly, there are studies specifying that there is either negative or positive relationship between irisin levels and metabolic syndrome/HOMA-IR. ${ }^{12}{ }^{13}$ There is a contradiction in this regard.

Until today, no studies have been performed to directly examine the relationship between circulating irisin levels, IR and subclinical atherosclerosis in BD after adjusting for potential confounders. Mounting evidence for irisin may contribute to the exploration of novel and effective therapeutic targets or therapeutic strategies. Therefore, the aim of present study was to evaluate whether circulating irisin was related to endothelial dysfunction and IR in patients with BD.

\section{MATERIAL AND METHODS}

\section{Study design and patient selection}

This prospective and observational study was conducted in the Rheumatology and Cardiology outpatient clinics of our hospital. Forty-eight female patients with BD and age-body mass index (BMI), muscle mass, and exercise condition (all individuals were under sedentary position), matched with 50 healthy female subjects as the control group, were enrolled in the study. The patients who had been diagnosed with BD according to International BD Study Group criteria were enrolled in the study (International study group for BD. Evaluation of diagnostic ('classification') criteria in $\mathrm{BD}$ disease towards internationally agreed criteria). ${ }^{14}$ Disease severity in the patients with BD was evaluated by using BD current activity form. ${ }^{15}$ Patients with concomitant systemic diseases such as diabetes mellitus, chronic obstructive lung disease, coronary artery disease, cancer, thyroid function disorder, hematological disorders, acute or chronic liver and renal diseases, acute or chronic infections, and a history of smoking and alcohol consumption, were excluded. Patients with BD who were included in this study were using only colchicine as a drug. We excluded patients with $\mathrm{BD}$ who were using drugs that can affect cIMT (such as steroids or statins). Healthy subjects with no regular use of medications, history of neither smoking nor alcohol consumption, and those who did not have a known disease, were involved as control group. The study was approved by the Ethical Committee of Our University Medical Faculty and the study was performed according to the Declaration of Helsinki. It was explained to all participants that cIMT measurement and serum analyses would not cost them any money, and blood samples collected for cIMT measurement and serum analyses would harm neither the patients nor those in the control group. After explaining these details, written consent of participants who agreed to join the study was obtained.

\section{Ultrasonographic examination method}

\section{Radiological imaging}

Following ultrasonographic detection of right and left arteries of patient and control groups, in supine position, carotid intima media thickness values were measured from right and left arteria carotis communis. cIMT measurement was carefully performed using a high-resolution ultrasound machine (Logiq S6; General Electric, Milwaukee, Wisconsin, USA) with a $12-\mathrm{MHz}$ mechanical sector transducer device by one radiologist who was blinded to the results of the blood tests. Three measurements were performed in systolic phase on three different points on the posterior wall of the artery, $2 \mathrm{~cm}$ proximal to the bifurcation of the arteria carotis communis. cIMT was calculated by using the average of these three measurements.

\section{Biochemical analysis}

Venous blood samples were obtained from all participants after 10-12 h fasting. Fasting plasma glucose (FPG), creatinine, alanine aminotransferase, total cholesterol (TC), triglyceride (TG), and high-density lipoprotein cholesterol (HDL-C) levels were measured using a Synchron LX20 system (Beckman Coulter, USA) and Beckman reagents. HDL-C levels were detected using a direct enzymatic method without precipitation. Low-density lipoprotein cholesterol levels were computed using the Friedewald formula. Hemoglobin level was determined using a Coulter Max M mode device. C reactive protein (CRP) levels were analyzed by an autoanalyser Synchron LX System (Beckman Coulter, Fullerton, California, USA). Erythrocyte sedimentation rate was determined by iSed (Alcor Scientific). Thyroid stimulating hormone (TSH) levels $(0.4-4 \mathrm{mU} / \mathrm{L}$ ) were determined using commercially available kits (DPC Diagnostics Products Corporation, Los Angeles, California, USA). Insulin resistance score, Homeostasis Model Assessment+Insulin Resistance (HOMA+IR), was calculated by FPG $(\mathrm{mmol} / \mathrm{L}) \times$ fasting serum insulin $(\mathrm{mU} / \mathrm{mL}) /$ 22.5 formula and 2.7 was accepted as cut-off value.

\section{Irisin measurements}

Venous blood samples were collected from all patients in the morning at 08:00 after a long-term rest. If blood 
samples for irisin are stored for a long period of time (eg, at $-80^{\circ} \mathrm{C}$ for 6 months), its levels will strongly effect; ${ }^{16}$ therefore, serum samples were stored for less than 3 months, after being evaluated immediately after collection. The concentration of irisin was assessed by using the ELISA method. We used a commercially available human irisin ELISA kit (Cusabio, PR China). The procedure applied for the ELISA method was consistent with the instructions provided by the manufacturer. Absorbance was measured at a wavelength of $450 \eta \mathrm{m}$ using an ELISA reader. Irisin levels were presented as $\mathrm{ng} / \mathrm{mL}$. The smallest detectable dose for irisin assay was $0.78 \mathrm{ng} / \mathrm{mL}$. Intra-assay coefficient of variation $(\mathrm{CV})$ was $<8 \%$ and inter-assay $\mathrm{CV}$ was $<10 \%$.

\section{Statistical analysis}

SPSS V.18 was used for statistical analysis. The results were presented as mean $\pm \mathrm{SD}$, median and minimum-maximum. Kolmogorov Smirnov test was used to determine if the groups were homogeneously distributed. Normally and non-normally distributed data were analyzed by Independent $\mathrm{T}$ test and Mann Whitney $\mathrm{U}$ test, respectively. Spearman correlation analysis test was used for correlation analysis. Multiple logistic regression analysis was implemented to detect the independent relationship between cIMT and irisin levels, and other parameters such as CRP, IR and BMI. $p$ Values $<0.05$ were accepted as significant.

\section{RESULTS}

\section{Baseline characteristics}

The patient group's age (36.7 \pm 11.5 years) and BMI $\left(26.1 \pm 4.2 \mathrm{~kg} / \mathrm{m}^{2}\right)$ values were similar to the control group's age $(36.4 \pm 12.0$ years $)$ and BMI $\left(25.6 \pm 4.2 \mathrm{~kg} / \mathrm{m}^{2}\right)$ values. In the patients with $\mathrm{BD}$, disease duration was $7.8 \pm 6.2$ years and disease activity index was found to be 3.0 (1.0-7.0). cIMT of the patient group was significantly higher than that of control group- $(0.62(0.45-1.05) \mathrm{mm}$ vs 0.38 $(0.25-0.65)(\mathrm{p}<0.001)$. Table 1 shows sociodemographic features of the patient and control groups.

The serum irisin level of the patients with BD (85.4 $(4.7-471.1) \mathrm{ng} / \mathrm{mL}$ ) was significantly lower when compared to the irisin level of the control group (197.3 (24.8-834.2) $\mathrm{ng} / \mathrm{mL}, \mathrm{p}=0.007$ ) (figure 1). In the patients with $\mathrm{BD}$, serum glucose (93.0 (72.0-122.0) $\mathrm{mg} / \mathrm{dL})$, insulin (13.4 \pm 7.4$)$, CRP (2.6 (0.5-43.0) mg/dL) and HOMA-IR (2.7 (0.8-7.5)) values were significantly higher than glucose $(88.0$ $(67.0-109.0) \quad \mathrm{mg} / \mathrm{dL}, \quad \mathrm{p}=0.005), \quad$ insulin $(9.6 \pm 4.7$, $\mathrm{p}=0.003)$, CRP $(1.2(0.2-5.0) \mathrm{mg} / \mathrm{dL}, \mathrm{p}<0.001)$, and HOMA-IR (1.7 (0.7-5.2), $\mathrm{p}=0.002)$ levels of the control group. All biochemical results of the patients with $\mathrm{BD}$ and control group patients are presented in table 2 .

When serum irisin $(\mathrm{ng} / \mathrm{mL})$ levels of the groups were compared according to activity score, no significant difference was detected between activity scores $1,2,3,4,5$ and higher, in terms of serum irisin level (45.8 (20.3 to 207.91); 23.5 (4.7 to 418.5); 167.8 (22.0 to 471.1), 51.4 (0.6 to 317.9 ); 67.0 (11.0 to 441.0 ), respectively, $\mathrm{p}>0.05$ in each).

\section{Correlation analysis}

There was a negative correlation between serum irisin level and $\operatorname{cIMT}(\mathrm{r}=-0.511, \mathrm{p}<0.001)$ (figure 2), insulin $(\mathrm{r}=$
Table 1 Sociodemographic characteristics of the patient and control groups

\begin{tabular}{|c|c|c|c|}
\hline & $\begin{array}{l}\text { Behçet's } \\
(n=48)\end{array}$ & Control $(n=50)$ & $\mathrm{p}$ Value \\
\hline Age (years) $($ mean $\pm S D)$ & $36.7 \pm 11.5$ & $36.4 \pm 12.0$ & 0.910 \\
\hline Gender (female/male) (n) & $17 / 31$ & $21 / 29$ & 0.323 \\
\hline BMI $\left(\mathrm{kg} / \mathrm{m}^{2}\right)(\operatorname{mean} \pm \mathrm{SD})$ & $26.1 \pm 4.2$ & $25.6 \pm 4.2$ & 0.546 \\
\hline $\begin{array}{l}\text { cIMT }(\mathrm{mm}) \text { (median } \\
\text { (range)) }\end{array}$ & $0.62(0.45-1.05)$ & $0.38(0.25-0.65)$ & 0.001 \\
\hline $\begin{array}{l}\text { Colchicine dose (median } \\
\text { (range)) }\end{array}$ & $1.5(0.0-2.0)$ & & \\
\hline $\begin{array}{l}\text { Disease duration (years) } \\
(\text { mean } \pm \text { SD) }\end{array}$ & $7.8 \pm 6.2$ & & \\
\hline $\begin{array}{l}\text { Disease Activity Score } \\
\text { (median (range)) }\end{array}$ & $3.0(1.0-7.0)$ & & \\
\hline Oral ulcers (\%) & 97.9 & & \\
\hline Articular involvement (\%) & 54.2 & & \\
\hline Follicular acne (\%) & 47.9 & & \\
\hline Pathergy (\%) & 45.8 & & \\
\hline Genital ulcers (\%) & 41.7 & & \\
\hline Ocular involvement (\%) & 33.3 & & \\
\hline Thrombophlebitis (\%) & 16.7 & & \\
\hline Arthritis (\%) & 12.5 & & \\
\hline Vascular involvement (\%) & 12.5 & & \\
\hline CNS involvement (\%) & 4.2 & & \\
\hline Erythema nodosum (\%) & 2.1 & & \\
\hline Renal involvement (\%) & 2.1 & & \\
\hline $\begin{array}{l}\text { Entero-Behçet's } \\
\text { disease (\%) }\end{array}$ & 0 & & \\
\hline Pulmonary aneurysm (\%) & 0 & & \\
\hline Vasculitis (\%) & 0 & & \\
\hline
\end{tabular}

-0.332, $\mathrm{p}=0.021)$, HOMA-IR $(\mathrm{r}=-0.371, \mathrm{p}=0.009)$ and creatinine $(r=-0.394, p=0.006)$. A positive correlation was detected between cIMT and insulin $(r=0.434$, $\mathrm{p}=0.002)$, HOMA-IR $(\mathrm{r}=0.527, \mathrm{p}<0.001)$, age $(\mathrm{r}=0.436$, $\mathrm{p}=0.002)$ and creatinine $(\mathrm{r}=0.419, \mathrm{p}=0.003)$ level. Table 3 shows all correlation results for irisin and cIMT. In

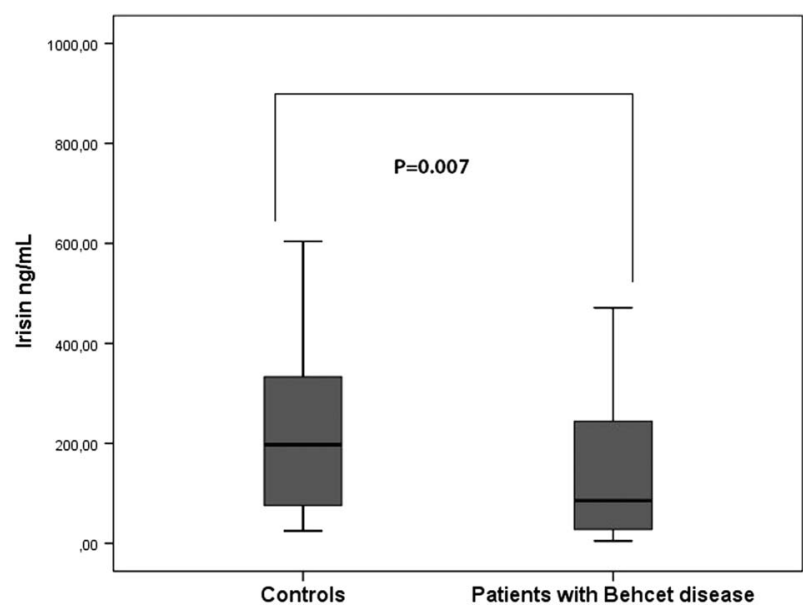

Figure 1 Serum irisin levels in BD and control groups. BD, Behçet's disease. 
Table 2 Biochemical parameters of the patient and control groups

\begin{tabular}{|c|c|c|c|}
\hline & Behçet's $(n=48)$ * & Control $(n=50)^{*}$ & p Value \\
\hline ALT IU/L & $22.9 \pm 13.9$ & $21.4 \pm 17.1$ & 0.626 \\
\hline Creatinine (mg/dL) & $0.78 \pm 0.1$ & $0.78 \pm 0.1$ & 0.969 \\
\hline $\begin{array}{l}\text { CRP (mg/dL) } \\
\text { (median (range)) }\end{array}$ & $2.6(0.5-43.0)$ & $1.2(0.2-5.0)$ & 0.001 \\
\hline $\operatorname{ESR}(\mathrm{mm} / \mathrm{h})$ & $10.1 \pm 9.9$ & $7.4 \pm 4.9$ & 0.090 \\
\hline $\begin{array}{l}\text { Glucose (mg/dL) } \\
\text { (median (range)) }\end{array}$ & $93.0(72.0-122.0)$ & $88.0(67.0-109.0)$ & 0.005 \\
\hline $\mathrm{Hb}(\mathrm{g} / \mathrm{dL})$ & $14.2 \pm 1.5$ & $14.5 \pm 1.5$ & 0.341 \\
\hline $\mathrm{HDL}-\mathrm{C}(\mathrm{mg} / \mathrm{dL})$ & $42.7 \pm 9.1$ & $43.6 \pm 8.4$ & 0.615 \\
\hline $\begin{array}{l}\text { HOMA-IR (median } \\
\text { (range)) }\end{array}$ & $2.7(0.8-7.5)$ & $1.7(0.7-5.2)$ & 0.002 \\
\hline Insulin $(\mu \mathrm{IU} / \mathrm{mL})$ & $13.4 \pm 7.4$ & $9.6 \pm 4.7$ & 0.003 \\
\hline $\begin{array}{l}\text { Irisin (ng/mL) } \\
\text { (median (range)) }\end{array}$ & $85.4(4.7-471.1)$ & $197.3(24.8-834.2)$ & 0.007 \\
\hline LDL-C (mg/dL) & $111.0 \pm 24.9$ & $118.4 \pm 22.4$ & 0.126 \\
\hline $\begin{array}{l}\text { Platelets } \\
\left(\times 10^{3} / \mathrm{mm}^{3}\right)\end{array}$ & $264.8 \pm 60.8$ & $282.5 \pm 66.2$ & 0.172 \\
\hline TC (mg/dL) & $184.5 \pm 30.4$ & $188.7 \pm 27.6$ & 0.474 \\
\hline TG (mg/dL) & $153.9 \pm 80.2$ & $133.5 \pm 72.9$ & 0.192 \\
\hline TSH (mU/L) & $1.7 \pm 1.1$ & $1.5 \pm 0.9$ & 0.544 \\
\hline WCC $\left(\times 10^{3} / \mathrm{mm}^{3}\right)$ & $7.7 \pm 2.8$ & $7.2 \pm 1.9$ & 0.351 \\
\hline \multicolumn{4}{|c|}{$\begin{array}{l}\text { *Mean } \pm \text { SD. } \\
\text { ALT, alanine aminotransferase; CRP, C reactive protein; ESR, erythrocyte } \\
\text { sedimentation rate; Hb, hemoglobin; HDL-C, high-density Lipoprotein } \\
\text { cholesterol; HOMA-IR, Homeostasis Model Assessment of Insulin Resistance; } \\
\text { LDL-C, low-density lipoprotein cholesterol; TC, total cholesterol; TG, } \\
\text { triglyceride; TSH, thyroid-stimulating hormone; WCC, white cell counts. }\end{array}$} \\
\hline
\end{tabular}

addition, a strong positive correlation was present between HOMA-IR and BMI $(r=0.362, p=0.012)$.

\section{Regression analysis}

Logistic regression analysis was performed using a cIMT-dependent variable. According to results of the

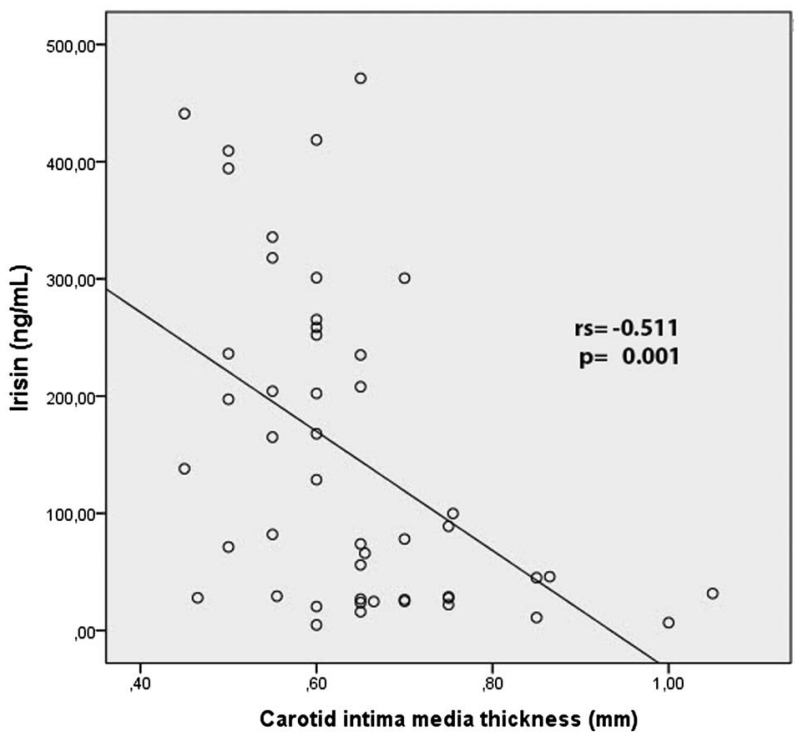

Figure 2 Correlation between serum irisin and carotid intima-media thickness.
Table 3 Correlation analysis of other factors in Behçet's disease patients with cIMT

\begin{tabular}{|c|c|c|c|c|}
\hline \multirow[b]{2}{*}{ Variable } & \multicolumn{2}{|l|}{ CIMT } & \multicolumn{2}{|l|}{ Irisin } \\
\hline & $r$ value & $p$ Value & $r$ value & $p$ Value \\
\hline Age & 0.436 & 0.002 & -0.265 & 0.068 \\
\hline ALT & 0.212 & 0.148 & -0.212 & 0.147 \\
\hline BMI & 0.152 & 0.301 & -0.132 & 0.370 \\
\hline Creatinine & 0.419 & 0.003 & -0.394 & 0.006 \\
\hline CRP & 0.081 & 0.584 & -0.213 & 0.145 \\
\hline Disease duration & 0.198 & 0.178 & 0.211 & 0.151 \\
\hline ESR & 0.074 & 0.615 & -0.089 & 0.546 \\
\hline Glucose & 0.011 & 0.940 & 0.051 & 0.730 \\
\hline $\mathrm{Hb}$ & 0.125 & 0.398 & 0.111 & 0.452 \\
\hline HDL-C & -0.056 & 0.705 & 0.076 & 0.606 \\
\hline HOMA-IR & 0.527 & 0.001 & -0.371 & 0.009 \\
\hline Insulin & 0.434 & 0.002 & -0.332 & 0.021 \\
\hline Irisin & -0.511 & 0.001 & & \\
\hline LDL-C & 0.188 & 0.200 & -0.109 & 0.461 \\
\hline Platelets & 0.159 & 0.279 & 0.053 & 0.721 \\
\hline TC & 0.166 & 0.260 & -0.094 & 0.527 \\
\hline TG & 0.152 & 0.301 & -0.116 & 0.434 \\
\hline TSH & 0.279 & 0.055 & -0.059 & 0.691 \\
\hline WCC & 0.093 & 0.532 & 0.152 & 0.303 \\
\hline
\end{tabular}

ALT, alanine aminotransferase; CRP, C reactive protein; ESR, erythrocyte sedimentation rate; $\mathrm{Hb}$, hemoglobin; $\mathrm{HDL}-\mathrm{C}$, high-density lipoprotein cholesterol; HOMA-IR, Homeostasis Model Assessment of Insulin Resistance; LDL-C, low-density lipoprotein cholesterol; TC, total cholesterol; TG, triglyceride; $\mathrm{TSH}$, thyroid-stimulating hormone; WBC, white cell counts.

logistic regression analysis, decreased serum irisin level (OR $0.996,95 \%$ CI 0.992 to $1.000, \mathrm{p}=0.041)$, male gender (OR 7.634, 95\% CI 1.415 to $41.191, \mathrm{p}=0.018$ ), and HOMA-IR (OR 2.596, 95\% CI 1.451 to $4.643, \mathrm{p}=0.001$ ) were independent risk factors of cIMT in patients with BD. Results of logistic regression analysis can be seen in table 4 .

\section{Subgroup analysis}

In subgroup analysis, cIMT of the patients with BD was higher in males when compared with that in females

Table 4 Multiple logistic regression analysis for CIMT in patients with Behçet's disease

\begin{tabular}{|c|c|c|c|}
\hline Independent variables & OR & $95 \% \mathrm{Cl}$ & p Value \\
\hline HOMA-IR & 2.596 & 1.451 to 4.643 & 0.001 \\
\hline Male gender & 7.634 & 1.415 to 41.191 & 0.018 \\
\hline Decreased irisin level & 0.996 & 0.992 to 1.000 & 0.041 \\
\hline CRP & 1.101 & 0.991 to 1.224 & 0.075 \\
\hline Glucose & 1.046 & 0.986 to 1.109 & 0.136 \\
\hline BMI & 1.136 & 0.939 to 1.374 & 0.191 \\
\hline Age & 0.961 & 0.894 to 1.034 & 0.287 \\
\hline Decreased HDL-C & 1.031 & 0.961 to 1.106 & 0.380 \\
\hline LDL-C & 0.970 & 0.904 to 1.041 & 0.397 \\
\hline TG & 1.004 & 0.989 to 1.018 & 0.617 \\
\hline Creatinine & 0.817 & 0.700 to 1.010 & 0.935 \\
\hline
\end{tabular}


$(\mathrm{p}=0.001)$, while serum irisin level was lower in males than in females $(p=0.023)$. cIMT was higher and irisin level was very low in patients with BD with IR when compared to patients with BD without IR. In subgroup analysis of healthy control subjects with regard to gender and IR, serum irisin levels were found to be similar in both genders, and among the patients with and without IR. Results of subgroup analysis are shown in table 5.

Furthermore, when subgroup analysis was performed according to HOMA-IR values, groups were as follows: group 1 (BMI $<25 \mathrm{~kg} / \mathrm{m}^{2}$ plus HOMA-IR $<2.7$ in $\mathrm{BD}$ ), group $2\left(\mathrm{BMI}<25 \mathrm{~kg} / \mathrm{m}^{2}\right.$ plus HOMA-IR $\geq 2.7$ in BD), group 3 (BMI $\geq 25 \mathrm{~kg} / \mathrm{m}^{2}$ plus HOMA-IR $<2.7$ in $\mathrm{BD}$ ), group 4 (BMI $\geq 25 \mathrm{~kg} / \mathrm{m}^{2}$ plus HOMA-IR $\geq 2.7$ in BD), group 5 (BMI $<25 \mathrm{~kg} / \mathrm{m}^{2}$ plus HOMA-IR $<2.7$ in control), group 6 (BMI $<25 \mathrm{~kg} / \mathrm{m}^{2}$ plus HOMA-IR $\geq 2.7$ in control), group 7 (BMI $\geq 25 \mathrm{~kg} / \mathrm{m}^{2}$ plus HOMA-IR $<2.7$ in control), group 8 (BMI $\geq 25 \mathrm{~kg} / \mathrm{m}^{2}$ plus HOMA-IR $\geq 2.7$ in control). There was a significant difference between group 4 and group $1(\mathrm{p}=0.025)$, group $5(p=0.003)$ and group $7(p=0.002)$, group 2 and group $5(\mathrm{p}=0.009)$, and group $7(\mathrm{p}=0.007)$. There was no significant difference between the other group pairs not mentioned above (all $\mathrm{p}>0.05$ ). Analysis results of all subgroups can be seen in table 5 .

\section{DISCUSSION}

Irisin is an exercise-induced myokine that is released from the liver, kidney, heart, skeletal muscles and skin. It has an active role in energy metabolism. ${ }^{9}{ }^{17}$ A low serum irisin level is related to many adverse conditions. Several studies have reported that, in patients with prediabetes and type II diabetes, irisin levels were lower than normal, and this was found to be related to hyperglycemia and hyperlipidemia. ${ }^{18} 19$ Low serum irisin levels play an important role in insulin sensitivity and decreased insulin secretion, development of IR and glucose-fatty acid metabolism disorders. ${ }^{20}$ Serum irisin levels were reported to be lower in diabetic patients with macrovascular complications compared to non-diabetic patients without macrovascular complication. ${ }^{21}$ Hyperglycemia, advanced-glycosylated end products, and IR accelerate the atherosclerotic process by causing direct endothelial dysfunction, augmenting cytokine release from endothelium, increasing lipid peroxidation and causing oxidative damage. ${ }^{22}$ Hyperglycemia, IR and chronic inflammation cause endothelial dysfunction and atherosclerosis in patients with $\mathrm{BD} .{ }^{23}{ }^{24}$ In our study, cIMT, serum CRP, glucose and HOMA-IR levels of the patients with $\mathrm{BD}$ were significantly higher when compared to those in the control group, while the serum irisin level was found to be very much lower in the BD group than in the healthy control group. There was positive correlation between age, serum creatinine, insulin, HOMA-IR and cIMT, while a negative correlation was detected between cIMT and serum irisin level. In addition, we found a negative correlation between HOMA-IR and irisin level. Our regression analysis results showed that decreased irisin level was a strong and predictive for HOMA-IR and cIMT. In the literature, Lee $e t a l^{11}$ detected significantly lower levels of serum irisin in patients receiving peritoneal dialysis when compared to those of healthy individuals, and found a strong correlation between serum irisin level and cIMT. However, it was stated in their study that irisin level might be associated with reduced muscle mass. We hypothesized that, since low irisin level may strongly related to IR and hyperglycemia, low serum irisin level should obviously be related to accelerated atherosclerosis. Therefore, we might find a strong association between low irisin levels and

Table 5 Subgroup analysis according to HOMA-IR, BMI and gender

\begin{tabular}{|c|c|c|c|c|c|c|}
\hline & \multicolumn{3}{|c|}{ Behçet's disease $(n=48)^{*}$} & \multicolumn{3}{|l|}{ Control group $(n=50)^{*}$} \\
\hline & Male $(n=31)$ & Female $(n=17)$ & p Value & Male $(n=29)$ & Female $(n=21)$ & $p$ Value \\
\hline cIMT (mm) & $0.65(0.47$ to 1.00$)$ & $0.60(0.45$ to 0.75$)$ & 0.001 & $0.45(0.25$ to 0.65$)$ & $0.30(0.25$ to 0.40$)$ & 0.001 \\
\hline Irisin $(\mathrm{ng} / \mathrm{mL})$ & 45.8 (6.6 to 471.2$)$ & 197.2 (4.7 to 441.0 ) & 0.023 & 179.9 (24.8 to 834.2$)$ & 218.8 (27.2 to 604.0$)$ & 0.945 \\
\hline BMI $\left(\mathrm{kg} / \mathrm{m}^{2}\right)$ & 24.9 (18.3 to 31.6$)$ & $29.2(21.2$ to 35.8$)$ & 0.009 & 25.7 (19.3 to 32.6$)$ & $24.9(18.6$ to 32.0$)$ & 0.945 \\
\hline \multirow[t]{2}{*}{ HOMA-IR } & $2.9(0.8$ to 7.5$)$ & 2.5 (1.1 to 6.2$)$ & 0.813 & 2.1 (0.7 to 5.2 ) & $1.6(0.7$ to 3.7$)$ & 0.331 \\
\hline & HOMA<2.7 $(n=24)$ & HOMA $\geq 2.7$ ( $n=24)$ & & HOMA<2.7 $(n=37)$ & HOMA $\geq 2.7(n=13)$ & \\
\hline clMT (mm) & $0.55(0.45$ to 0.75$)$ & $0.66(0.55$ to 1.05$)$ & 0.001 & $0.38(0.25$ to 0.65$)$ & $0.37(0.25$ to 0.55$)$ & 0.973 \\
\hline Irisin $(\mathrm{ng} / \mathrm{mL})$ & 235.6 (20.3 to 471.1$)$ & $45.4(4.7$ to 418.5$)$ & 0.002 & 218.8 (27.0 to 834.2 ) & 129.1 (24.8 to 585.6 ) & 0.095 \\
\hline BMI $\left(\mathrm{kg} / \mathrm{m}^{2}\right)$ & 24.7 (18.3 to 30.3$)$ & 27.7 (19.2 to 35.8$)$ & 0.027 & 22.9 (19.0 to 31.2$)$ & 25.7 (18.6 to 32.6$)$ & 0.041 \\
\hline \multirow[t]{2}{*}{ HOMA-IR } & $2.0(0.9$ to 2.6$)$ & 4.3 (2.8 to 7.5$)$ & 0.001 & $1.5(0.7$ to 2.5$)$ & $3.4(2.7$ to 5.2$)$ & 0.001 \\
\hline & $\begin{array}{l}\text { BMI }<25\left(\mathrm{~kg} / \mathrm{m}^{2}\right) \\
\text { HOMA-IR<2.7 }(\mathrm{n}=16)\end{array}$ & $\begin{array}{l}\text { BMI }<25\left(\mathrm{~kg} / \mathrm{m}^{2}\right) \\
\text { HOMA-IR } \geq 2.7(\mathrm{n}=8)\end{array}$ & & $\begin{array}{l}\text { BMI }<25\left(\mathrm{~kg} / \mathrm{m}^{2}\right) \\
\text { HOMA-IR<2.7 }(\mathrm{n}=17)\end{array}$ & $\begin{array}{l}\text { BMI }<25\left(\mathrm{~kg} / \mathrm{m}^{2}\right) \\
\text { HOMA-IR } \geq 2.7(\mathrm{n}=8)\end{array}$ & \\
\hline \multirow[t]{2}{*}{ Irisin (ng/mL) } & 247.6 (20.3 to 441.0$)$ & 48.7 (15.9 to 207.9) & 0.057 & 198.3 (30.9 to 589.2 ) & 148.7 (24.8 to 585.6 ) & 0.147 \\
\hline & $\begin{array}{l}\text { BMI } \geq 25\left(\mathrm{~kg} / \mathrm{m}^{2}\right) \\
\text { HOMA-IR<2.7 }(\mathrm{n}=8)\end{array}$ & $\begin{array}{l}\text { BMI } \geq 25\left(\mathrm{~kg} / \mathrm{m}^{2}\right) \\
\text { HOMA-IR } \geq 2.7(\mathrm{n}=16)\end{array}$ & & $\begin{array}{l}\text { BMI } \geq 25\left(\mathrm{~kg} / \mathrm{m}^{2}\right) \\
\text { HOMA-IR<2.7 }(\mathrm{n}=20)\end{array}$ & $\begin{array}{l}\text { BMI } \geq 25\left(\mathrm{~kg} / \mathrm{m}^{2}\right) \\
\text { HOMA-IR } \geq 2.7(\mathrm{n}=5)\end{array}$ & \\
\hline Irisin (ng/mL) & 138.0 (22.0 to 471.1$)$ & $45.8(4.7$ to 418.5$)$ & 0.440 & 259.4 (27.0 to 834.2 ) & 112.6 (45.4 to 374.6 ) & 0.169 \\
\hline
\end{tabular}


cIMT. Unlike our study and other studies showing that a low level of serum irisin is related to IR, some studies state that increased irisin levels are associated with IR and cIMT. $^{12}{ }^{25}$ It was reported that an increased irisin level prevented endothelial dysfunction in diabetic patients by decreasing the formation of peroxynitrite and superoxide radicals. ${ }^{8}$ Sesti $e t a l^{25}$ reported that a high serum irisin level was related to cIMT; however, the patient group in their study consisted completely of healthy subjects with no cardiac disease and no diabetes.

The subgroup analysis can provide information about the relationship between low irisin levels and IR. In our study, serum irisin level was lower in obese and overweight patients with $\mathrm{BD}$ with $\mathrm{IR}$, and in lean patients with $\mathrm{BD}$ with $\mathrm{IR}$, compared to obese and overweight $\mathrm{BD}$ patients without IR, and to lean patients with BD without IR. In addition, serum irisin level was very low in obese and overweight controls with IR, and in lean controls with IR when compared to obese and overweight controls without IR, and lean controls without IR. We found low serum irisin levels in both, patients with $\mathrm{BD}$ and healthy individuals; particularly in patients with IR other than obesity. Irisin is mainly secreted from myocytes and it may not be a good indicator for the amount of the BMI for muscle tissue since BMI will be high in individuals with high fat tissue even though they have a low amount of muscle tissue. According to our hypothesis, there is a strong relationship between IR and low irisin levels, and decreased irisin levels may lead to atherosclerosis via increasing IR. This could be the case because we found that IR was a strong independent risk factor for cIMT according to the regression analysis results.

Male gender is a risk factor for disease severity and atherosclerotic cardiac diseases in $\mathrm{BD} .{ }^{26}$ Many studies have revealed no correlation between genders, age and serum irisin level. ${ }^{27}$ On the other hand, Anastasilakis et $a l^{28}$ reported that serum irisin level was significantly lower in lean males than in lean females. In regression analysis of our study, male gender was found to be an independent risk factor for cIMT. We also found that the serum irisin level was lower but cIMT was higher in male patients with BD when compared to female patients. Some studies reported a positive correlation between LDL, TC and irisin, ${ }^{20}$ while the findings of other studies have not supported this. In the study by Wen et al, ${ }^{29}$ a high level of correlation was detected between low serum irisin levels and low HDL level in patients with chronic renal failure. In our study, we did not find any correlation between lipid panel and serum irisin level.

In contrast to a few studies, ${ }^{30}$ Liu $e t ~ a l^{31}$ found a positive correlation between glomerular filtration rate and low serum irisin level in patients with type II diabetes, and the authors reported that progressive decrease in muscle mass and increased level of uremic toxins might decrease irisin release in chronic renal failure. In our study, we also detected a negative correlation between serum irisin level and creatinine level. Moreover, there was a strong positive correlation between creatinine level and cIMT. Renal involvement is known to be common in patients with $\mathrm{BD}$, and glomerulonephritis, amyloidosis, renal vascular involvement and interstitial nephritis may develop. ${ }^{32}$ In patients with $\mathrm{BD}$, a low irisin level might increase renal damage by causing hyperglycemia and IR.
Unlike our study, some studies, interestingly, showed cardioprotective effects of low serum irisin levels. Some studies have reported that a low serum irisin level plays a protective role in acute coronary events such as myocardial infarction by decelerating energy metabolism of myocardial tissue, and decreasing tissue oxygenation and ATP expenditure. ${ }^{33}$ Kuloglu et $a l^{34}$ reported that high irisin levels cause ATP loss during uncoupled biochemical reactions. However, low irisin levels are known to be cardioprotective. In another study, it was reported that the level of irisin was lower during the first 2 days of myocardial infarction and it increased after the 72 nd hour of infarction. $^{35}$

\section{Limitations of the study}

First, we had a relatively small sample size. Second, disease activity indexes of patients with $\mathrm{BD}$ were comparatively low and it is possible that the correlation between the high disease activity index, low number of patients and serum irisin levels may have influenced our results. Third, duration of the BD disease and active arthritis patient numbers were, relatively, not high. An increment in disease duration can affect cIMT. Furthermore, duration of the disease and arthritis affected the exercise status of patients, and thus irisin levels could be influenced. There should be further broader studies regarding this issue.

\section{Conclusion}

Irisin is an adipocytokine that is related to energy metabolism, insulin sensitivity and release. We found that serum irisin levels in patients with $\mathrm{BD}$ had a negative relationship with cIMT, which is a well-known indicator for IR and subclinical atherosclerosis. It is possible that low irisin levels in patients with $\mathrm{BD}$ can be associated with atherosclerosis. Since our study is the first to evaluate serum irisin and cIMT in patients with $\mathrm{BD}$, further studies are required in this field.

Competing interests None declared.

Patient consent Obtained.

Ethics approval Necmettin Erbakan University.

Provenance and peer review Not commissioned; externally peer reviewed

Open Access This is an Open Access article distributed in accordance with the Creative Commons Attribution Non Commercial (CC BY-NC 4.0) license, which permits others to distribute, remix, adapt, build upon this work noncommercially, and license their derivative works on different terms, provided the original work is properly cited and the use is non-commercial. See: http:// creativecommons.org/licenses/by-nc/4.0/

\section{REFERENCES}

1 Gürgün C, Ercan E, Ceyhan C, et al. Cardiovascular involvement in Behcet's disease. Jpn Heart J 2002;43:389-98.

2 Hingorani $A D$, Cross J, Kharbanda RK, et al. Acute systemic inflammation impairs endothelium-dependent dilatation in humans. Circulation 2000;102:994-9.

3 Haraoui B, Liu PP, Papp KA. Managing cardiovascular risk in patients with chronic inflammatory diseases. Clin Rheumatol 2012;31:585-94.

4 Balta I, Balta S, Demirkol S, et al. Elevated serum levels of endocan in patients with psoriasis vulgaris: correlations with cardiovascular risk and activity of disease. Br J Dermatol 2013;169:1066-70.

5 Erden I, Demir B, Ucak H, et al. Serum salusin-alpha and salusin-beta levels in patients with Behcet's disease. Eur J Dermatol 2014;24:577-82.

6 Yalcin B, Gur G, Artuz F, et al. Prevalence of metabolic syndrome in Behcet disease: a case-control study in Turkey. Am J Clin Dermatol 2013;14:421-5. 
7 Moreno-Navarrete JM, Ortega F, Serrano M, et al. Irisin is expressed and produced by human muscle and adipose tissue in association with obesity and insulin resistance. J Clin Endocrinol Metab 2013;98:769-78.

8 Zhu D, Wang H, Zhang J, et al. Irisin improves endothelial function in type 2 diabetes through reducing oxidative/nitrative stresses. J Mol Cell Cardiol 2015;87:138-47.

9 Xie C, Zhang Y, Tran TD, et al. Irisin controls growth, intracellular Ca2+ signals, and mitochondrial thermogenesis in cardiomyoblasts. PLOS ONE 2015; 10:e0136816.

10 Kwasniewska M, Kozinska J, Dziankowska-Zaborszczyk E, et al. The impact of long-term changes in metabolic status on cardiovascular biomarkers and microvascular endothelial function in middle-aged men: a 25 -year prospective study. Diabetol Metab Syndr 2015;7:81.

11 Lee MJ, Lee SA, Nam BY, et al. Irisin, a novel myokine is an independent predictor for sarcopenia and carotid atherosclerosis in dialysis patients. Atherosclerosis 2015;242:476-82.

12 Park KH, Zaichenko L, Brinkoetter $\mathrm{M}$, et al. Circulating irisin in relation to insulin resistance and the metabolic syndrome. J Clin Endocrinol Metab 2013;98:4899-907.

13 Yan $B$, Shi $X$, Zhang $H$, et al. Association of serum irisin with metabolic syndrome in obese Chinese adults. PLOS ONE 2014;9:e94235.

14 [No authors listed]. Criteria for diagnosis of Behcet's disease. International Study Group for Behcet's Disease. Lancet 1990;335:1078-80.

15 Bhakta BB, Brennan P, James TE, et al. Behcet's disease: evaluation of a new instrument to measure clinical activity. Rheumatology (Oxford) 1999;38:728-33.

16 http://www.mybiosource.com/images/tds/protocol_others/MBS7239246.pdf

17 Wu F, Song $H$, Zhang $Y$, et al. Irisin induces angiogenesis in human umbilical vein endothelial cells in vitro and in Zebrafish Embryos in vivo via activation of the ERK signaling pathway. PLOS ONE 2015;10:e0134662.

18 Wang HH, Zhang XW, Chen WK, et al. Relationship between serum irisin levels and urinary albumin excretion in patients with type 2 diabetes. J Diabetes Complicat 2015;29:384-9.

19 Zhang C, Ding Z, Lv G, et al. Lower irisin level in patients with type 2 diabetes mellitus: a case-control study and meta-analysis. J Diabetes 2016;8:56-62.

20 Liu JJ, Wong MD, Toy WC, et al. Lower circulating irisin is associated with type 2 diabetes mellitus. J Diabetes Complicat 2013;27:365-9.
21 Zhang $\mathrm{M}$, Chen $\mathrm{P}$, Chen $\mathrm{S}$, et al. The association of new inflammatory markers with type 2 diabetes mellitus and macrovascular complications: a preliminary study. Eur Rev Med Pharmacol Sci 2014;18:1567-72.

22 Tabas I, Tall A, Accili D. The impact of macrophage insulin resistance on advanced atherosclerotic plaque progression. Circ Res 2010;106:58-67.

23 Erdem $\mathrm{H}$, Dinc A, Pay $\mathrm{S}$, et al. Peripheral insulin resistance in patients with Behcet's disease. J Eur Acad Dermatol Venereol 2006:20:391-5.

24 Ozgen M, Koca SS, Aksoy K, et al. Visfatin levels and intima-media thicknesses in rheumatic diseases. Clin Rheumatol 2011;30:757-63.

25 Sesti G, Andreozzi F, Fiorentino TV, et al. High circulating irisin levels are associated with insulin resistance and vascular atherosclerosis in a cohort of nondiabetic adult subjects. Acta Diabetol 2014;51:705-13.

26 Messedi M, Frigui M, Ben Mahfoudh K, et al. Intima-media thickness of carotid artery in patients with Behcet's disease. Arch Med Res 2011;42:398-404.

27 Reinehr T, Elfers C, Lass $N$, et al. Irisin and its relation to insulin resistance and puberty in obese children: a longitudinal analysis. I Clin Endocrinol Metab 2015;100:2123-30.

28 Anastasilakis AD, Polyzos SA, Saridakis ZG, et al. Circulating irisin in healthy, young individuals: day-night rhythm, effects of food in take and exercise, and associations with gender, physical activity, diet, and body composition. J Clin Endocrinol Metab 2014;99:3247-55.

29 Wen MS, Wang CY, Lin SL, et al. Decrease in irisin in patients with chronic kidney disease. PLOS ONE 2013;8:e64025.

30 Espes D, Lau J, Carlsson PO. Increased levels of irisin in people with long-standing Type 1 diabetes. Diabet Med 2015;32:1172-6.

31 Liu JJ, Liu S, Wong MD, et al. Relationship between circulating irisin, renal function and body composition in type 2 diabetes. I Diabetes Complicat 2014;28:208-13.

32 Zheng W, Li G, Zhou M, et al. Renal involvement in Chinese patients with Behcet's disease: a report of 16 cases. Int I Rheum Dis 2015;18:892-7.

33 Emanuele E, Minoretti P, Pareja-Galeano $\mathrm{H}$, et al. Serum irisin levels, precocious myocardial infarction, and healthy exceptional longevity. Am J Med 2014;127:888-90.

34 Kuloglu T, Aydin S, Eren MN, et al. Irisin: a potentially candidate marker for myocardial infarction. Peptides 2014;55:85-91.

35 Aydin S, Aydin S, Kobat MA, et al. Decreased saliva/serum irisin concentrations in the acute myocardial infarction promising for being a new candidate biomarker for diagnosis of this pathology. Peptides 2014;56:141-5. 